\title{
Eficiência de fluridone no Controle de Plantas Aquáticas Submersas e Efeitos sobre Algumas Características Ambientais ${ }^{1}$
}

\author{
Fluridone Efficacy in Controling Submersed Aquatic Weeds and its Effects on Some \\ Environmental Characteristics
}

\author{
MARCONDES, D.A.S. ${ }^{2}$, VELINI, E.D. ${ }^{3}$, MARTINS, D. ${ }^{3}$, TANAKA, R.H. ${ }^{2}$, CARVALHO, F.T. ${ }^{4}$, \\ CAVENAGHI, A.L. ${ }^{5}$ e BRONHARA, A.A. ${ }^{6}$
}

\begin{abstract}
RESUMO - O objetivo deste estudo foi avaliar a eficiência do herbicida fluridone no controle de plantas aquáticas submersas (Egeria densa, Egeria najas e Ceratophyllum demersum), assim como seus efeitos sobre algumas características ambientais. A pesquisa foi conduzida no reservatório da Usina Hidrelétrica Eng. Souza Dias (Jupiá), região noroeste do Estado de São Paulo, em uma reentrância denominada lagoa Vírgula. A lagoa foi dividida em nove faixas e seis delas receberam uma aplicação inicial de fluridone para se obter uma concentração de 20 ppb. As aplicações subseqüentes foram dimensionadas para recompor esta concentração. Para o estudo do carreamento do herbicida pelo fluxo de água, foi efetuado o monitoramento das suas concentrações nas nove faixas da lagoa (com e sem aplicação) e em áreas a jusante e a montante. Foram analisados os efeitos do fluridone sobre características ambientais como: turbidez, temperatura da água, condutividade elétrica, concentração de oxigênio, pH e resíduos de fluridone. A eficácia do controle foi avaliada visualmente (pelos sintomas de fitointoxicação nas três espécies estudadas) e pela amostragem de biomassa. Observou-se que o fluridone controlou de forma satisfatória E. najas e E. densa. Quando cessou o efeito do fluridone, aconteceu a reinfestação de $E$. densa e $E$. najas. Não houve controle de C. demersum. O fluridone não produziu efeitos adversos sobre as características de qualidade ambiental estudadas.
\end{abstract}

Palavras-chave: fluridone, macrófita aquática, Egeria densa, Egeria najas, Ceratophyllum demersum.

\begin{abstract}
This study aimed to evaluate the efficacy of the herbicide fluridone to control submersed aquatic weeds (Egeria densa, Egeria najas and Ceratophyllum demersum), as well as its effects on some environmental characteristics. The research was carried out in the reservoir of Eng. Souza Dias (Jupiá) Hydro-elecric plant power, Station in northwestern São Paulo, Brazil, in Lagoa Virgula bay. The bay was divided in nine zones and six of them received an initial application of fluridone to achieve the concentration of $20 \mathrm{ppb}$. The amounts of fluridone used in all other applications were calculated to restore the $20 \mathrm{ppb}$ concentration. In order to study the herbicide loss due to water flow, fluridone concentrations were monitored in all treated and non-treated zones of the bay and in upstream and downstream areas. Fluridone effects on some environmental characteristics, such as turbidity, water temperature, electric conductivity, oxigen concentration, $\mathrm{pH}$ and fluridone residues were evaluated. Visual evaluation of phytotoxicity symptoms on the three species studied and biomass evaluations were also carried out. Fluridone controlled the submersed aquatic plants $\boldsymbol{E}$. najas and E. densa. E. densa and E. najas regrew as the effect of fluridone ended while $\boldsymbol{C}$. demersum was not controlled. Fluridone did not produce any negative effect on the environmental quality characteristics studied in the treated areas.
\end{abstract}

Key words: fluridone, aquatic macrophyte, Egeria densa, Egeria najas, Ceratophyllum demersum.

1 Recebido para publicação em 4/1/2001 e na forma revisada em 18/1/2002.

Parte da Tese de Livre-Docência do primeiro autor.

2 Eng.-Agr., Companhia Energética de São Paulo, Rua da Consolação, 1875, 01301-100 São Paulo-SP. ${ }^{3}$ Prof. Assistente Doutor, Dep. de Produção Vegetal, FCA-UNESP, Caixa Postal 237, 18603-970 Botucatu-SP. ${ }^{4}$ Prof. Assistente Doutor, FEIS-UNESP. ${ }^{5}$ Eng.-Agr., Dr., Dep. de Produção Vegetal, FCA-UNESP. ${ }^{6}$ Eng.-Agr., Álvaro Alvares Abreu Silva Filho, 45, 13066-110 Campinas-SP. 


\section{INTRODUÇÃO}

Décadas de desmatamento e conservação inadequada dos solos proporcionaram o carreamento de nutrientes para os leitos de rios e reservatórios. A erosão de solos agrícolas, juntamente com parte dos fertilizantes, além da carga de esgotos urbanos e industriais, vêm desequilibrando os cursos e reservatórios de água devido à grande disponibilidade de nutrientes, que aceleram o crescimento da vegetação aquática. Embora uma quantidade desta vegetação seja necessária como fonte de oxigênio, alimento e abrigo para a vida aquática, grandes infestações podem dificultar os usos da água pelo homem, além de dificultar a própria vida no ambiente aquático.

No Brasil, talvez o maior de todos os problemas seja a infestação pelas espécies Egeria densa, Egeria najas e Ceratophyllum demersum do reservatório da Usina Hidrelétrica Eng. Souza Dias (Jupiá), operado pela Companhia Energética de São Paulo (CESP). Nos períodos chuvosos, as cheias deslocam grandes massas de plantas, que podem alcançar as grades de proteção das turbinas da usina. Caso a limpeza não seja feita em tempo, a obstrução das grades pode gerar a ruptura ou sucção de painéis das grades de proteção (Marcondes et al., 1997).

Duas destas espécies (E. densa e C. demersum) são freqüentemente citadas entre as plantas submersas que mais provocam danos em diversas regiões do planeta. Holm \& Yeo (1980) consideraram que as espécies submersas mais importantes pertencem aos gêneros Hydrilla, Myriophyllum, Ceratophyllum, Egeria, Elodea, Potamogeton e Vallisneria.

Segundo Chapman et al. (1974), o deslocamento de infestações de C. demersum em direção a usinas hidrelétricas da Nova Zelândia provocava a interrupção da geração de energia, pois os equipamentos de remoção mecânica eram incapazes de manter as grades das turbinas limpas. Neste mesmo país, HowardWilliams et al. (1996) afirmaram que lagos e rios sofreram invasões de plantas submersas exóticas, formando grandes infestações monoespecíficas, em substituição às espécies nativas. As principais invasoras eram C. demersum e membros da família Hydrocharitaceae, principalmente E. densa. Wells et al. (1997) relataram que E. densa e
C. demersum eliminaram, no período de dez anos, todas as outras espécies no lago Tarawera (Nova Zelândia), em profundidades maiores que 2 metros, com predomínio de $E$. densa a até $10 \mathrm{~m}$ e de $C$. demersum entre 10 e $14,5 \mathrm{~m}$ de profundidade.

Em razão dos prejuízos causados por estas plantas aos usos da água, o controle do crescimento populacional destas é fundamental. O objetivo deste estudo foi avaliar a eficiência do herbicida fluridone no controle de plantas submersas que ocorrem no reservatório de Jupiá, assim como os efeitos causados em algumas características ambientais.

\section{MATERIAL E MÉTODOS}

O estudo foi desenvolvido no reservatório de Jupiá, numa área denominada lagoa Vírgula, que é uma reentrância do reservatório de Jupiá, com coordenadas geográficas de $20^{\circ}$ 40 ' $10,1^{\prime \prime}$ S e $51^{\circ} 21^{\prime} 13,8$ "W, na margem direita do rio Tietê, e possui superfície de 28,8 ha. Foi considerada como testemunha uma lagoa localizada a montante da área experimental. As espécies-alvo foram $E$. densa, E. najas e C. demersum. Na época do estudo, a lagoa apresentava elevado nível de infestação pelas três espécies e nenhuma das plantas exibia qualquer sintoma de estresse.

O herbicida utilizado foi o fluridone (1metil3-fenil-5-[3-(trifluorometil)-fenil]-4-(1H)piridinona), que é um composto sistêmico e tem como mecanismo de ação a inibição da síntese de carotenóides (Sprecher et al., 1998). A marca comercial utilizada foi Sonar AS, concentrado solúvel (480 g do i.a. fluridone $\mathrm{L}^{-1}$ )

As aplicações foram realizadas utilizandose um barco motorizado, ao qual foi acoplado um sistema de aplicação de herbicidas composto de: motor a gasolina, bomba e barra de aplicação com três mangueiras com pontas injetoras, que ficavam submersas na água. As mangueiras apresentavam comprimentos diferenciados, para que o herbicida fosse injetado na coluna d'água em três profundidades $(0,2$; 0,6; e 1,2 m). Durante a aplicação, o barco deslocou-se a uma velocidade de $8 \mathrm{~km} \mathrm{~h}^{-1}$, controlada com auxílio de um aparelho de GPS. A vazão total nas três pontas injetoras foi de $8 \mathrm{~L} \mathrm{minuto}^{-1}$, o que proporcionou volume de aplicação de $54 \mathrm{~L} \mathrm{ha}^{-1}$ de calda. 
A lagoa foi dividida em nove faixas, sendo seis delas tratadas e as três restantes utilizadas para avaliações de qualidade da água e resíduos do herbicida (Figura 1). As faixas receberam uma aplicação inicial de herbicida, com a qual procurou-se atingir uma concentração de $20 \mathrm{ppb}$. As aplicações subseqüentes de fluridone foram dimensionadas para recompor esta concentração.

Inicialmente, o estudo consideraria as faixas 1 a 6 . Como a variação de nível d'água durante o estudo foi muito grande, em razão de diferentes vazões na Usina Três Irmãos, verificou-se a impossibilidade de manter $20 \mathrm{ppb}$ na faixa 6. Nesta faixa, procurou-se fracionar a dose, entre a $4^{\mathrm{a}}$ e a $7^{\mathrm{a}}$ aplicação, mas também não foi suficiente para manter as concentrações desejadas. A faixa 5 recebeu aplicações até o final do estudo, com fracionamento da dose na oitava aplicação. Como as condições inicialmente previstas no estudo só puderam ser mantidas nas faixas 1 a 4 , somente estas foram consideradas como áreas efetivamente tratadas.

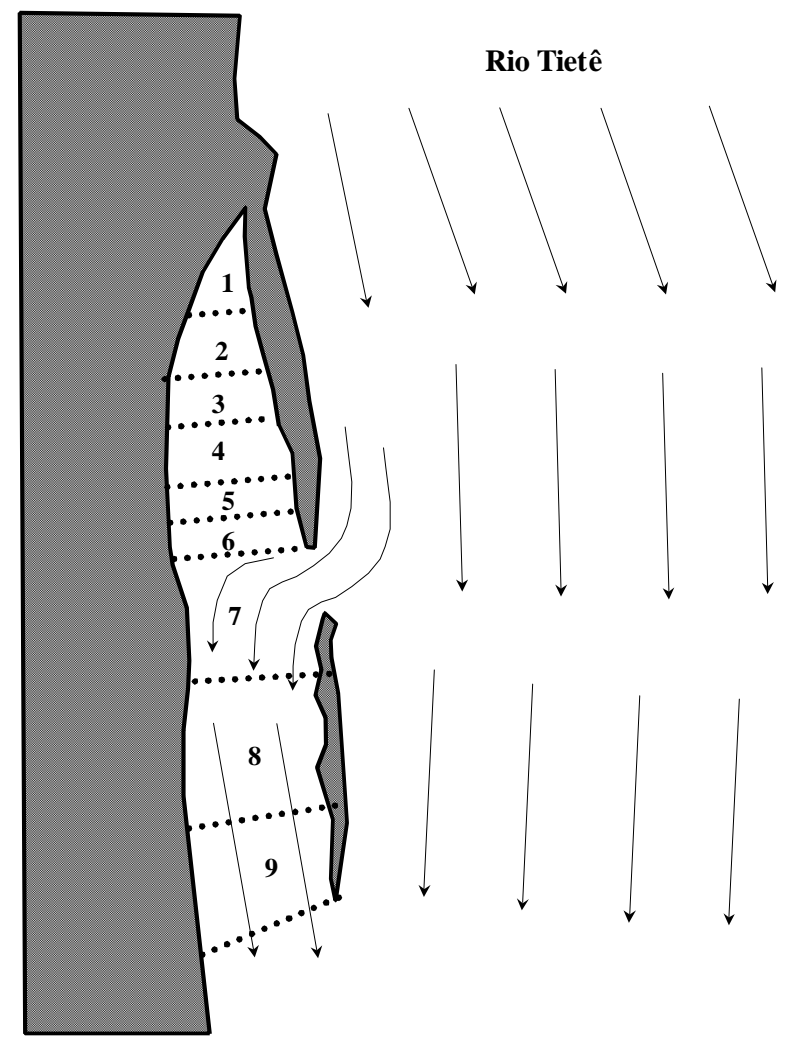

Figura 1 - Representação esquemática da lagoa Vírgula. As setas indicam a direção do fluxo de água. Os números de 1 a 9 representam as faixas de divisão da lagoa.
As épocas das aplicações foram: 1ạ: 22/8/ 1999; 2a: 30/8/1999; 3ㄹ: 6/9/1999; 4a: 13/9/ 1999; 5: 20/9/1999; 6ㄹ: 27/9/1999; 7a: 4/ 10/1999; 8a: 11/10/1999; 9a: 19/11/1999; 10: 2/12/1999; 11aa:22/12/1999; 12a: 10/01/ 2000 .

Na Figura 2 estão apresentadas as concentrações de fluridone ao longo da semana, tomando-se por referencial a concentração verificada na segunda-feira. As concentrações no dia "O" são estimativas para os domingos, logo após a aplicação. As concentrações no dia "7" representam as concentrações determinadas nos domingos, antes das aplicações. A determinação das quantidades de fluridone aplicadas semanalmente, nas faixas 1 a 6 , foi feita a partir das equações de regressão e das concentrações do herbicida obtidas durante a semana. As equações de regressão eram modificadas com a inclusão de novas informações a cada semana. Os coeficientes de determinação oscilaram entre 0,9483 (na primeira semana) e 0,9998 .

Além do fracionamento das aplicações nas faixas 5 e 6, outra modificação foi adotada em 19/9/1999: a redução da concentração máxima de fluridone de $20 \mathrm{ppb}$ para $15 \mathrm{ppb}$, de acordo com os valores encontrados por Smith \& Pullman (1997) e Fox et al. (1994) e teve como justificativa a intensidade dos sintomas observados.

Na Tabela 1 são apresentadas as quantidades de produto comercial utilizado para o tratamento de cada faixa, a cada aplicação, para atingir as concentrações desejadas (20 ou $15 \mathrm{ppb})$.

O método cromatográfico utilizado neste trabalho para determinação da concentração de fluridone em água foi desenvolvido e validado no laboratório de Matologia da Faculdade de Ciências Agronômicas da UNESP, campus de Botucatu-SP. O método utiliza extração em fase sólida e posterior limpeza e concentração do fluridone das amostras e quantificação por CLAES (cromatografia a líquido de alta eficiência). O método apresenta recuperação média de $94,9 \%$, incerteza inferior a $2 \%$ para a faixa de concentrações testada e limite de determinação de 50 ng L $\mathrm{L}^{-1}$.

Para o estudo do carreamento do herbicida pelo fluxo de água, foi realizado o monitoramento 
das suas concentrações nas nove faixas da lagoa Vírgula, em duas tomadas de sistemas de irrigação (distantes $11,25 \mathrm{~km}$ e 13,47 km da lagoa Vírgula, respectivamente), na praia localizada na cidade de Itapura (distante $16,59 \mathrm{~km}$ ) e na foz do rio Tietê (distante $22,22 \mathrm{~km}$ ). Exceto a lagoa testemunha, as outras áreas encontram-se a jusante da lagoa Vírgula. Nestes locais, foram verificados os efeitos do fluridone sobre outras características ambientais, destacando-se a temperatura da água, a condutividade elétrica, a concentração de oxigênio, o pH e a turbidez.
As avaliações da eficácia de controle das plantas-alvo consistiram de observações visuais dos sintomas de intoxicação nas plantasalvo não-alvo, além de avaliações de biomassa. As avaliações visuais foram efetuadas em todas as ocasiões em que foram feitas aplicações e amostragens de água até maio de 2000. A avaliação de biomassa foi realizada doze meses após o início da aplicação, com auxílio de um equipamento construído para este fim. Foram coletadas 16 amostras na lagoa testemunha, 10 na faixa 4 (com controle irregular) e 7 nas faixas 1 a 3 e 5 a 9 .

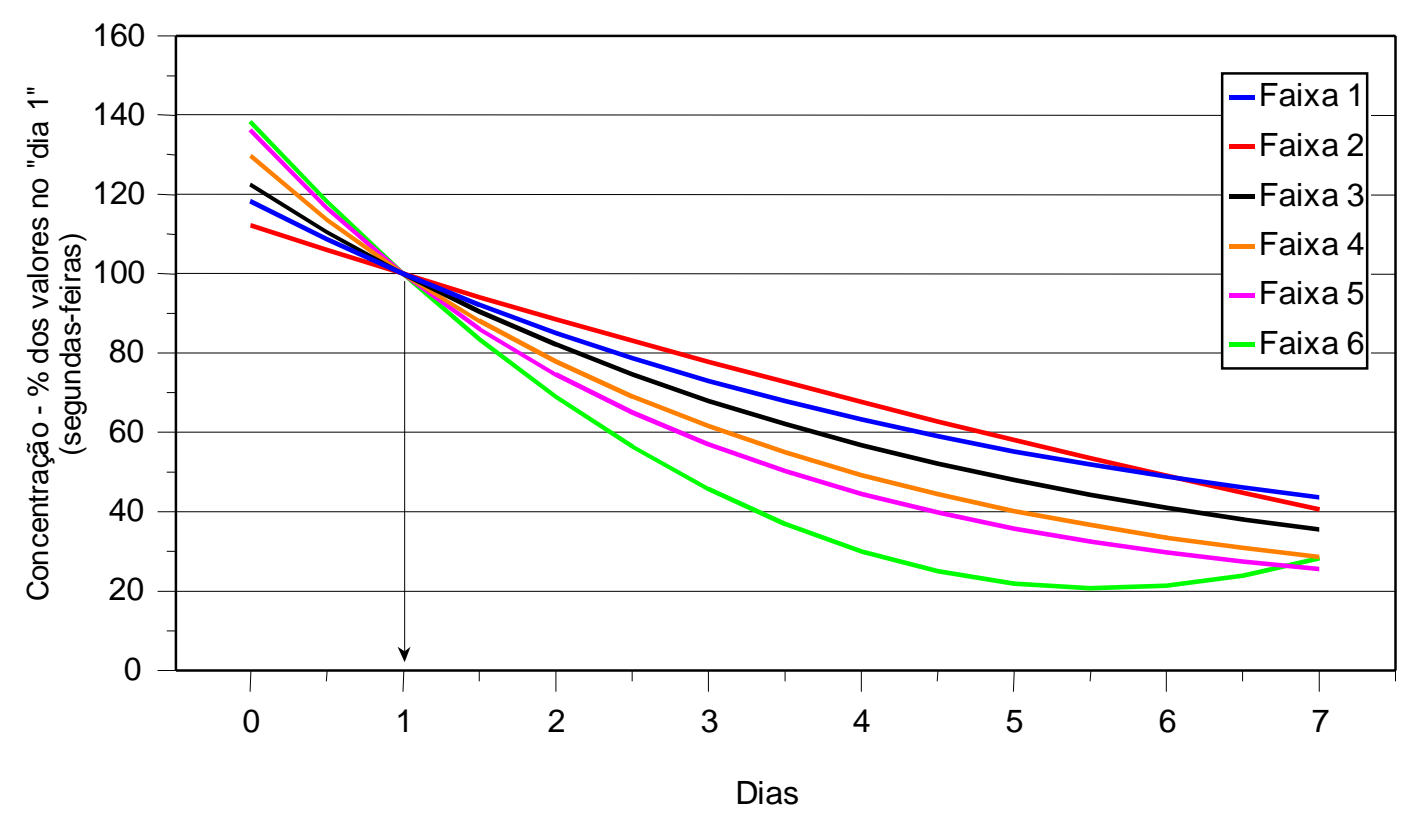

Figura 2 - Concentrações (ppb) de fluridone em porcentagens dos valores observados nas segundas-feiras, na lagoa Vírgula.

Tabela 1 - Volumes de fluridone aplicados em diferentes faixas e em cada aplicação (em litros do produto comercial), para atingir as concentrações desejadas

\begin{tabular}{|c|c|c|c|c|c|c|c|c|c|c|c|c|c|}
\hline \multirow{2}{*}{ Faixa } & \multicolumn{10}{|c|}{ Aplicação } \\
\cline { 2 - 12 } & 1 & 2 & 3 & 4 & 5 & 6 & 7 & 8 & 9 & 10 & 11 & 12 & Total \\
\hline 1 & 3,01 & 1,44 & 1,13 & 1,29 & 0,75 & 1,12 & 1,67 & 2,11 & 2,25 & 2,25 & 1,04 & 0,87 & 18,93 \\
2 & 2,73 & 1,14 & 1,10 & 1,45 & 0,77 & 1,27 & 1,74 & 2,17 & 2,20 & 2,20 & 1,03 & 0,99 & 18,79 \\
3 & 3,12 & 1,74 & 1,66 & 2,01 & 1,06 & 1,61 & 2,24 & 2,52 & 2,68 & 2,68 & 1,27 & 1,10 & 23,69 \\
4 & 3,62 & 2,26 & 2,19 & 2,33 & 1,38 & 1,74 & 2,48 & 2,78 & 2,94 & 2,94 & 1,36 & 1,18 & 27,20 \\
5 & 3,08 & 2,37 & 2,32 & 2,18 & 1,44 & 1,71 & 2,39 & 2,92 & 2,75 & 2,75 & 1,36 & 1,01 & 26,28 \\
6 & 3,09 & 2,40 & 2,42 & 2,12 & 1,46 & 1,56 & 2,06 & & & & & & 15,11 \\
\hline Total & 18,65 & 11,35 & 10,82 & 11,38 & 6,86 & 9,01 & 12,58 & 12,50 & 12,82 & 12,82 & 6,06 & 5,15 & 130,00 \\
\hline
\end{tabular}


As plantas foram colocadas em sacos de tela plástica, para escoamento da água. Depois de separadas, as plantas das três espécies-alvo foram pesadas para se obter o peso da matéria fresca. No laboratório, as plantas foram secas em estufa de renovação forçada de ar, com temperatura entre 70 e $75^{\circ} \mathrm{C}$, até peso constante. Em seguida, obteve-se o peso da matéria seca em cada amostragem.

Para a comparação dos valores de biomassa, foram adotados procedimentos não-paramétricos. Os valores de biomassa presentes em cada faixa foram comparados com os da lagoa testemunha, com auxílio do teste "T" em nível de $5 \%$ de probabilidade.

\section{RESULTADOS E DISCUSSÃO}

Nas Figuras 3 a 5 são apresentadas as informações de concentrações de fluridone nas faixas tratadas ( 1 a 6) e não-tratadas da lagoa Vírgula (7 a 9). Na Tabela 2 são apresentadas as informações referentes às médias para as concentrações máximas e mínimas, além das concentrações médias durante todo o período de controle (com final estabelecido em dez dias após a última aplicação).

Os valores referentes a concentrações máximas, mínimas e médias decrescem lentamente, sendo relativamente uniformes, na seqüência de faixas de 1 a 4 . Considerando as faixas que receberam tratamentos, não necessariamente por todo o período experimental, os maiores decréscimos para estas características (maiores reduções nos valores expressos em porcentagem das faixas anteriores) são observados nas transições entre as faixas $4 \mathrm{e}$ 5 e 5 e 6 . Pode-se concluir pela relativa uniformidade das concentrações de fluridone nas faixas 1 a 4 e pela grande diferença dos valores encontrados nestas faixas e os verificados nas faixas 5 e 6 . Em todas as situações, as informações de concentrações nas faixas 7 a 9 são muito inferiores aos valores observados nas demais unidades experimentais (faixas 1 a 6).

Na Figura 6 são apresentadas as informações de concentrações de fluridone na lagoa testemunha e em quatro pontos localizados a jusante da área com aplicação de fluridone: tomada de água de dois sistemas de irrigação, praia de Itapura e foz do rio Tietê. Os procedimentos de amostragem e analíticos foram os mesmos utilizados nas áreas tratadas. As datas de amostragem, posteriores a aplicações do herbicida (durante a fase com tratamento), foram selecionadas para maximizar a probabilidade de ocorrência do herbicida nesses pontos. Deve ser destacada a ausência do fluridone na lagoa testemunha, indicando que esta foi mantida completamente sem controle das espécies em estudo.

Nos demais pontos de monitoramento, as concentrações foram sempre bastante baixas e muito inferiores a $1 \mathrm{ppb}$, em termos médios, não ocorrendo qualquer efeito que pudesse ser associado à presença do fluridone.

Nas Tabelas 3 e 4 são apresentados os valores médios de biomassa encontrados na avaliação realizada 12 meses após o início do estudo e as porcentagens de controle de cada espécie, respectivamente.

Observa-se que reduções significativas de biomassa e níveis satisfatórios de eficiência foram alcançados para E. densa e E. najas nas faixas 1 a 4 . Não se observaram reduções significativas de biomassa e níveis satisfatórios de controle de $C$. demersum em qualquer das unidades experimentais. Na faixa 5, com aplicação do herbicida durante todo o período de controle, houve redução significativa somente da biomassa de E. najas, mas mesmo assim a porcentagem de controle desta espécie foi de apenas 59,8\%. A justificativa para os menores níveis de eficiência foi a elevada taxa de troca da água desta faixa, impossibilitando a manutenção da faixa de concentrações inicialmente prevista (oscilação entre 20 e 5 ppb).

Nas Tabelas 5 a 7 são apresentados os valores dos indicadores de qualidade da água em três épocas distintas: início, meio e final do experimento. Foram avaliadas as seguintes características: turbidez, oxigênio dissolvido, temperatura, $\mathrm{pH}$ e condutividade elétrica.

As avaliações indicaram que, a partir de outubro, os valores de temperatura foram menores na lagoa testemunha. Na presença das plantas, grande parte da radiação foi captada por esetas, enquanto na lagoa Vírgula a radiação dissipou-se na coluna d'água. Os valores de condutividade elétrica da lagoa testemunha foram inferiores aos das faixas tratadas. A morte das macrófitas e a posterior decomposição contribuíram para a liberação dos elementos retidos pelas plantas. 


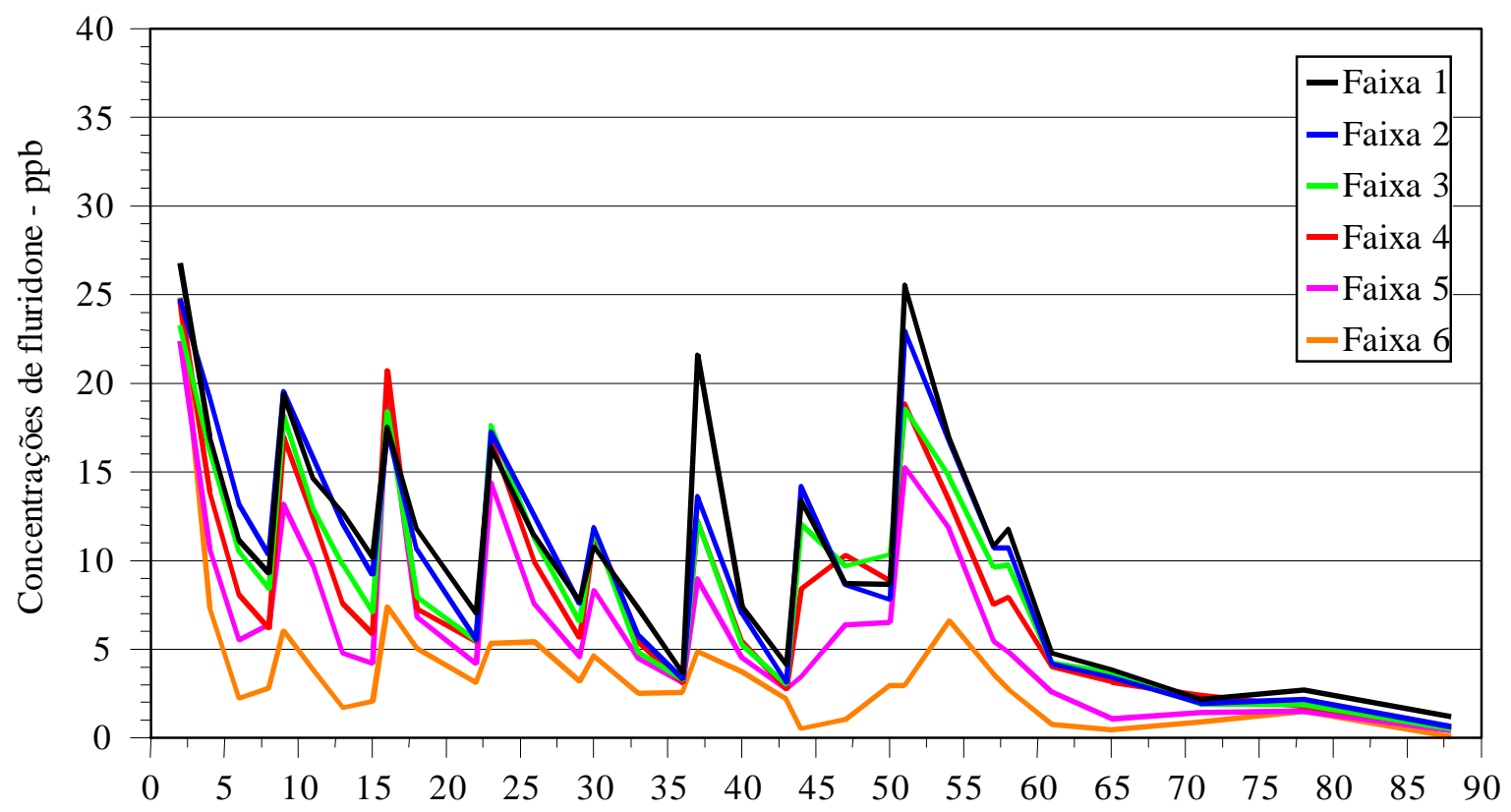

Dias após o início das aplicações (22/8/99)

Figura 3 - Concentrações de fluridone na água das faixas 1 a 6. Aplicações: 1 a 8.

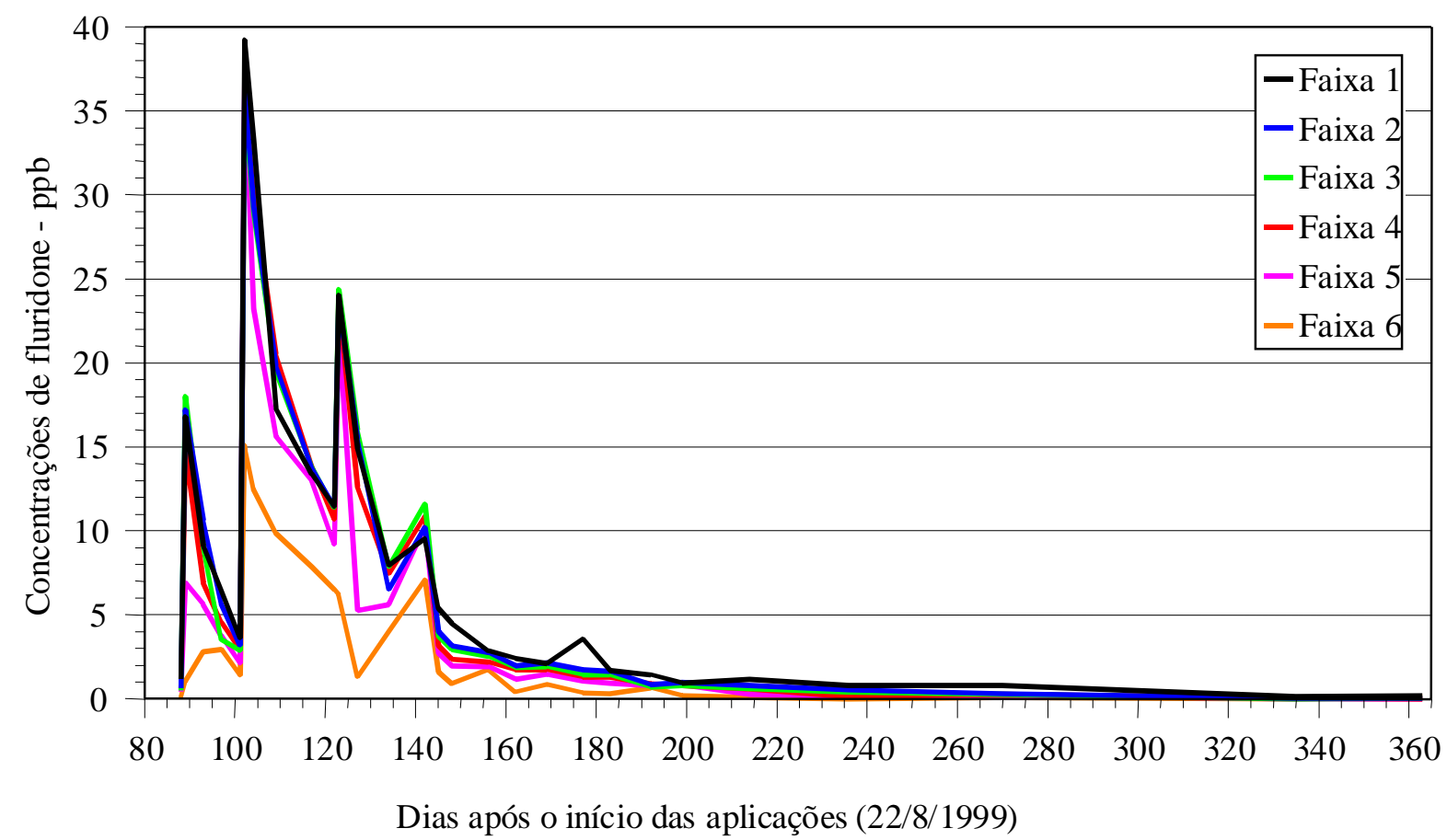

Figura 4 - Concentrações de fluridone na água das faixas 1 a 6. Aplicações: 9 a 12. 


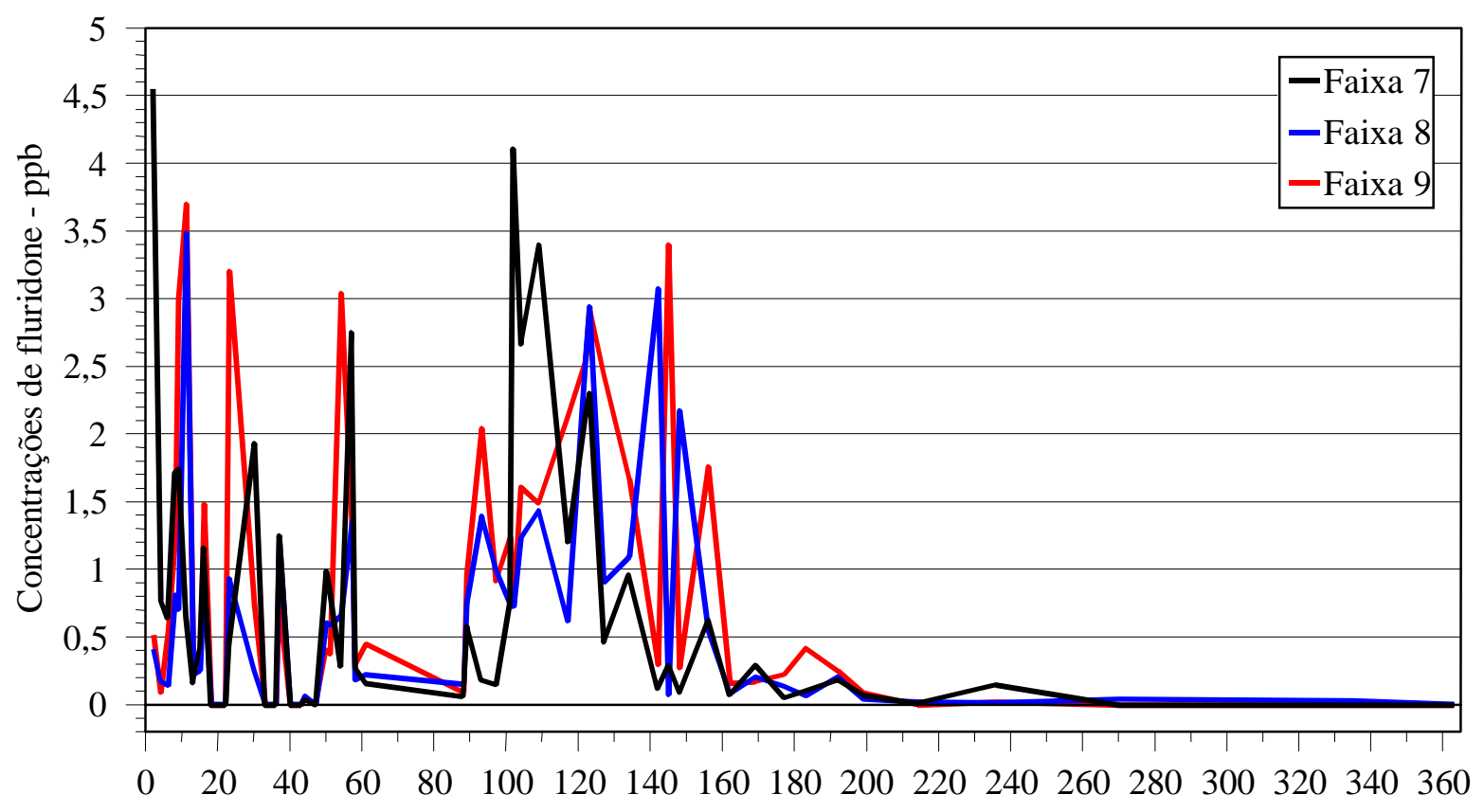

Dias após o início das aplicações (22/8/99)

Figura 5 - Concentrações de fluridone na água das faixas 7 a 9. Aplicações: 1 a 12.

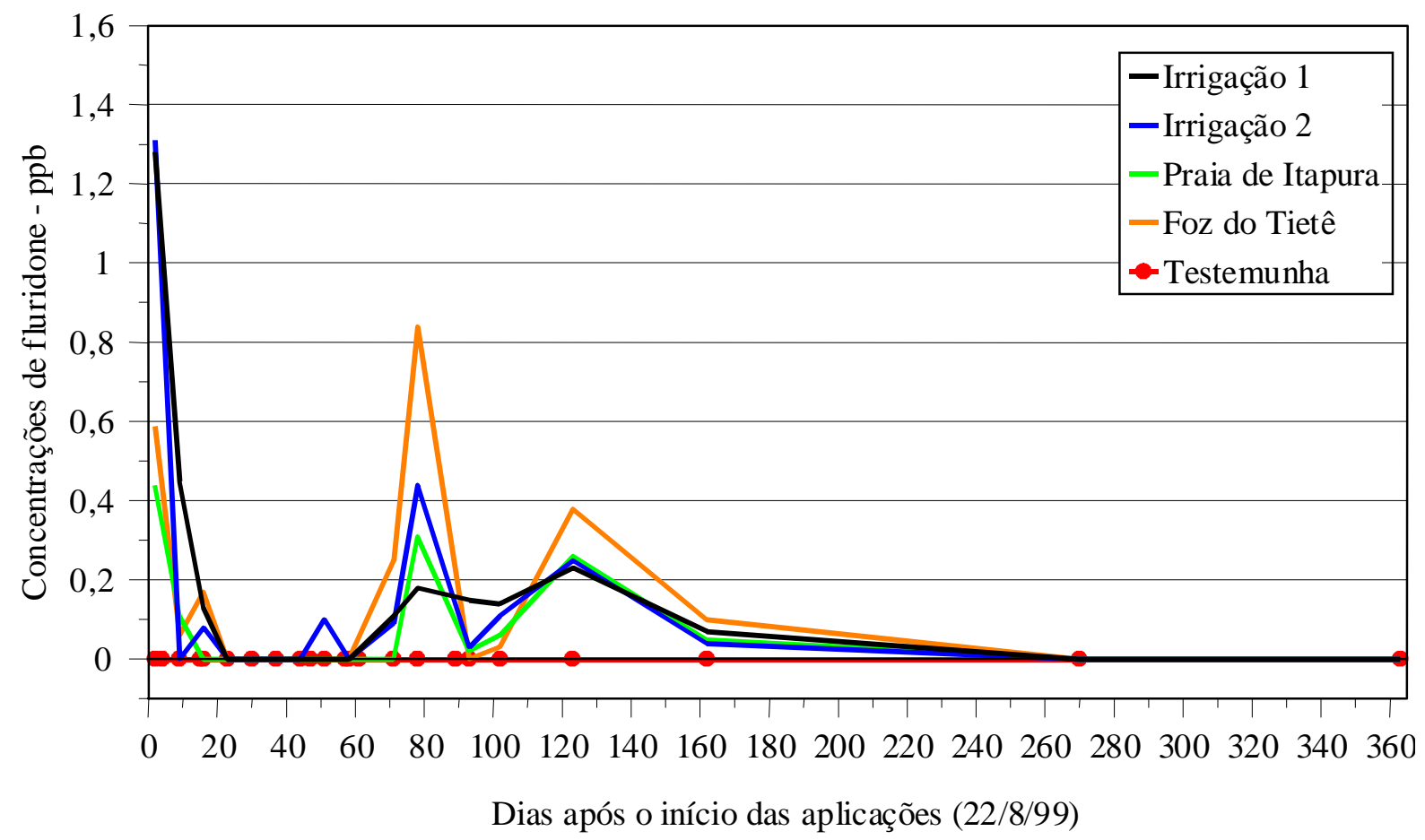

Figura 6 - Concentrações de fluridone em locais sem aplicação. Aplicações: 9 a 12. 
Tabela 2 - Valores médios para as concentrações (ppb) máximas, mínimas e médias de fluridone (IA) em cada faixa experimental durante o período de controle. Valores expressos em porcentagem dos valores encontrados para faixas imediatamente anteriores

\begin{tabular}{|c|c|c|r|}
\hline \multirow{2}{*}{ Faixas } & \multicolumn{3}{|c|}{ Concentrações de fluridone (ppb) } \\
\cline { 2 - 3 } & \multicolumn{2}{|c|}{ Médias para valores } & \multirow{2}{*}{ Médias } \\
\cline { 2 - 3 } & Máximos & Mínimos & \\
\hline 1 & 21,1 & 6,3 & 10,1 \\
2 & 19,9 & 5,7 & 9,7 \\
3 & 19,1 & 5,5 & 9,0 \\
4 & 18,6 & 4,9 & 8,5 \\
5 & 15,6 & 4,0 & 6,8 \\
6 & 7,2 & 2,4 & 3,6 \\
7 & 1,7 & 0,5 & 0,8 \\
8 & 0,9 & 0,4 & 0,7 \\
9 & 1,3 & 0,6 & 0,9 \\
\hline
\end{tabular}

Logo após o início das aplicações, a concentração de oxigênio dissolvido da lagoa testemunha suplantou as observadas nas faixas 2 e 4. Independentemente das variações, os valores de oxigênio dissolvido sempre estiveram em condições de suportar uma intensa atividade biótica no reservatório.

Os resultados obtidos no esperimento demonstraram que: a exposição contínua a concentrações de fluridone entre 4,9 e $21,1 \mathrm{ppb}$, por um período de 12 meses, reduziu significativamente a biomassa e permitiu atingir níveis de controle de Egeria densa e Egeria najas entre 81,3 e 100\%; os niveis de concentração de fluridone presentes nas faixas tratadas com o herbicida demonstraram a impossibilidade de controle da Ceratophyllum demersum; e o fluridone não produziu qualquer efeito adverso sobre as características de qualidade ambiental estudadas.

Tabela 4 -Porcentagens de controle de Egeria densa, Egeria najas e Ceratophyllum demersum na avaliação realizada de 9 a 18/8/2000

\begin{tabular}{|c|c|c|c|c|}
\hline \multirow{2}{*}{ Faixa } & \multicolumn{3}{|c|}{ \% de controle de egéria } & \multirow{2}{*}{ \% controle de } \\
\cline { 2 - 4 } & E. densa & E. najas & Total & C. demersum \\
\hline 1 & 98,0 & 98,4 & 98,2 & - \\
2 & 99,1 & 95,8 & 97,7 & - \\
3 & 97,4 & 97,3 & 97,3 & - \\
4 & 81,3 & 89,8 & 85,1 & - \\
5 & - & 59,8 & - & - \\
6 & - & - & - & - \\
\hline
\end{tabular}

Tabela 5 - Valores de indicadores de qualidade da água nas lagoas Vírgula e testemunha no início do experimento (21/8/1999, antes da $1^{\text {a }}$ aplicação)

\begin{tabular}{|l|c|c|c|c|c|}
\hline Local & Turbidez & $\begin{array}{c}\text { Oxigênio } \\
\text { dissolvido } \\
(\mathrm{NTU})\end{array}$ & $\begin{array}{c}\text { Tempe- } \\
\text { ratura } \\
\left(\mathrm{mg} \mathrm{L}^{-1}\right)\end{array}$ & $\mathrm{pH}$ & $\begin{array}{c}\text { Conduti- } \\
\text { vidade } \\
\text { elétrica } \\
\left(\mu \mathrm{Cm}^{-1}\right)\end{array}$ \\
\hline Faixa 1 & 1,56 & 6,54 & 20 & 7,45 & 68 \\
Faixa 2 & 0,90 & 6,88 & 20 & 7,35 & 70 \\
Faixa 3 & 0,80 & 7,37 & 20 & 7,40 & 70 \\
Faixa 4 & 1,23 & 7,57 & 21 & 7,45 & 69 \\
Faixa 5 & 0,50 & 7,20 & 22 & 7,35 & 72 \\
Faixa 6 & 0,00 & 7,16 & 23 & 7,25 & 70 \\
Faixa 7 & 0,00 & 7,22 & 22 & 7,40 & 70 \\
Faixa 8 & 0,00 & 7,21 & 22 & 7,30 & 70 \\
Faixa 9 & 0,00 & 7,18 & 22 & 7,35 & 70 \\
Testemunha & 1,27 & 6,50 & 25 & 7,40 & 72 \\
\hline
\end{tabular}

Tabela 3 - Acúmulos de biomassa fresca $\left(\mathrm{kg} \mathrm{ha}^{-1}\right)$ e teores médios de umidade de Egeria densa, Egeria najas e Ceratophyllum demersum na avaliação realizada de 9 a 18/8/2000

\begin{tabular}{|c|c|c|c|c|}
\hline \multirow{2}{*}{ Faixa } & \multicolumn{3}{|c|}{ Biomassa de Egeria } & \multirow{2}{*}{$\begin{array}{l}\text { Biomassa de } \\
\text { C. demersum }\end{array}$} \\
\hline & E. densa & E. najas & Total & \\
\hline 1 & $172,1 \quad b$ & $111,6 \quad \mathrm{c}$ & $283,7 \quad b$ & $19.827,1 \quad a b$ \\
\hline 2 & $74,6 \quad b$ & $281,2 \quad c$ & $355,8 \quad b$ & $12.462,5 \mathrm{ab}$ \\
\hline 3 & $228,0 \quad b$ & $183,6 \quad \mathrm{c}$ & $411,7 \quad b$ & $21.978,9 a b$ \\
\hline 4 & $1.617,3 \quad b$ & $689,4 \quad c$ & $2.306,7 \quad b$ & $30.559,5$ a \\
\hline 5 & $9.251,8 \mathrm{a}$ & $2.724,1 \quad b c$ & $11.975,8 \mathrm{a}$ & $13.480,3 \mathrm{ab}$ \\
\hline 6 & $12.111,6 \mathrm{a}$ & $4.927,0 \mathrm{ab}$ & $17.038,5 \mathrm{a}$ & $4.725,6 \quad b$ \\
\hline Testemunha & $8.660,3$ a & $6.770,5 \mathrm{a}$ & $15.430,8 \mathrm{a}$ & $6.923,3$ \\
\hline 7 & $3.561,7$ & $4.270,2$ & $7.831,9$ & 569,1 \\
\hline 8 & $7.679,7$ & $5.492,5$ & $13.172,1$ & $4.235,3$ \\
\hline 9 & $2.663,9$ & 706,5 & $3.370,4$ & $18.750,6$ \\
\hline Teores de água $(\%)$ & 94,3 & 94,1 & 94,2 & 93,9 \\
\hline
\end{tabular}


Tabela 6 - Valores de indicadores de qualidade da água nas lagoas Vírgula e testemunha no meio do experimento (6/10/1999, antes da $8^{-}$aplicação)

\begin{tabular}{|l|c|c|c|c|c|}
\hline Local & Turbidez & $\begin{array}{c}\text { Oxigênio } \\
\text { dissolvido } \\
\left(\mathrm{mg} \mathrm{L}^{-1}\right)\end{array}$ & $\begin{array}{c}\text { Tempe- } \\
\text { ratura } \\
\left({ }^{\circ} \mathrm{C}\right)\end{array}$ & $\mathrm{pH}$ & $\begin{array}{c}\text { Conduti- } \\
\text { vidade } \\
\text { elétrica } \\
\left(\mu \mathrm{S} \mathrm{cm}^{-1}\right)\end{array}$ \\
\hline Faixa 1 & 0,81 & 5,8 & 24 & 6,8 & 100 \\
Faixa 2 & 1,10 & 6,2 & 24 & 6,8 & 100 \\
Faixa 3 & 1,08 & 6,8 & 25 & 7,1 & 90 \\
Faixa 4 & 1,00 & 7,3 & 24 & 7,2 & 80 \\
Faixa 5 & 0,76 & 7,4 & 25 & 6,7 & 90 \\
Faixa 6 & 0,67 & 7,0 & 25 & 7,2 & 80 \\
Faixa 7 & 0,79 & 7,3 & 25 & 7,2 & 80 \\
Faixa 8 & 0,54 & 7,5 & 25 & 7,5 & 70 \\
Faixa 9 & 0,31 & 7,6 & 25 & 7,8 & 70 \\
Testemunha & 0,94 & 7,3 & 25 & 7,6 & 70 \\
\hline
\end{tabular}

\section{AGRADECIMENTOS}

A todas as pessoas que colaboraram na instalação e condução deste estudo, em especial: CESP (André Luiz Mustafá, Agnaldo Dias, Aguinaldo Lima Moraes Jr., Carlos José Rodrigues, Flávio Luís da Silva Jr., Haruo Kuratami, José Hélio Luppi Jr., René Alberto fuster Belmont, Renato Gomes da Motta, Sérgio Bovolenta, Valery Wanderley de Paiva e equipe de hidrologia), FCAV-UNESP (Prof. Dr. Robinson Antônio Pitelli), FCA-UNESP (Marco Antonio de Souza e Silva, Eduaro Negrisoli e Marcelo Andreotti) e SEPRO (Hans Rapp).

\section{LITERATURA CITADA}

CHAPMAN, V. J. et al. Biology of excessive weed growth in the hydro-electric lakes of the Waikato River, New Zealand. Hydrobiologia, v. 44, n. 4, p. 349-363, 1974.

FOX, A. M.; HALLER, W. T.; SHILLING, D. G. Use of fluridone for hydrilla management in the Withlacoochee River, Flórida. J. Aquatic. Plant Manag., v. 32, p. 47-55, 1994.
Tabela 7 - Valores de indicadores de qualidade da água nas lagoas Vírgula e testemunha no final do experimento $(1 / 4 / 2000)$

\begin{tabular}{|l|c|c|c|c|c|}
\hline Local & Turbidez & $\begin{array}{c}\text { Oxigênio } \\
\text { dissolvido } \\
(\mathrm{NTU})\end{array}$ & $\begin{array}{c}\text { Tempe- } \\
\text { ratura } \\
\left(\mathrm{mg} \mathrm{L}^{-1}\right)\end{array}$ & $\left.\mathrm{pH}{ }^{\circ} \mathrm{C}\right)$ & $\begin{array}{c}\text { Conduti- } \\
\text { vidade } \\
\text { elétrica } \\
\left(\mu \mathrm{S} \mathrm{cm}^{-1}\right)\end{array}$ \\
\hline Faixa 1 & 1,83 & 3,6 & 27 & 6,9 & 155 \\
Faixa 2 & 2,21 & 5,0 & 27 & 6,9 & 162 \\
Faixa 3 & 2,11 & 5,0 & 28 & 7,0 & 124 \\
Faixa 4 & 2,01 & 5,1 & 27 & 7,3 & 121 \\
Faixa 5 & 1,36 & 5,4 & 28 & 7,0 & 114 \\
Faixa 6 & 0,76 & 5,1 & 29 & 7,4 & 109 \\
Faixa 7 & 0,93 & 5,7 & 30 & 7,4 & 106 \\
Faixa 8 & 1,00 & 5,5 & 30 & 7,2 & 106 \\
Faixa 9 & 1,73 & 6,4 & 31 & 7,4 & 107 \\
Testemunha & 1,53 & 6,9 & 30 & 7,2 & 107 \\
\hline
\end{tabular}

HOLM, L.; YEO, R. The biology, control and utilization of aquatic weeds, part I. Weeds Today, p. 7-13, 1980.

HOWARD-WILLIAMS, C. et al. Patterns of aquatic weed regrowth following mechanical harvesting in New Zealand hydro-lakes. Hydrobiologia, v. 340, n. 1-3, p. 229-234, 1996.

MARCONDES, D. A. S. et al. Problemas com plantas daninhas aquáticas submersas em reservatórios de usinas hidrelétricas do complexo CESP. In: CONGRESSO BRASILEIRO DA CIÊNCIA DAS PLANTAS DANINHAS, 21, 1997, Caxambu. Resumos... Viçosa-MG: Sociedade Brasileira da Ciência das Plantas Daninhas, 1997. p. 334.

SMITH, C. S.; PULLMAN, G. D. Experiences using Sonar registered A.S. aquatic herbicide in Michigan. Lake

Reserv. Manag., v. 13, n. 4, p. 338-346, 1997.

SPRECHER, S. L.; NETHERLAND, M. D.; STEWART, A. B. Phytoene and carotene response of aquatic plants to fluridone under laboratory conditions. J. Aquatic. Plant Manag., v. 36, p. 111-120, 1998.

WELLS, R. D. S.; DE WINTON, M. D.; CLAYTON, J. S. Successive macrophyte invasions within the submerged flora of Tarawera, central North Island, New Zealand. N. Z. J. Mar. Freshwat. Res., v. 31, n. 4, p. 449-459, 1997. 